\title{
$\mathfrak{I n}$ nalts-1)erzeidutis.
}

Deutide 和oetik. 刃nitter T.eil.

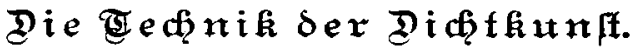

cinleitung als pllormort.

\section{Erftes fianptftiud: Heimlo[e, auf dem Khythmus beruhende

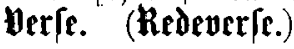

I. ป̂̉burgen im jambildyen trigythmus.

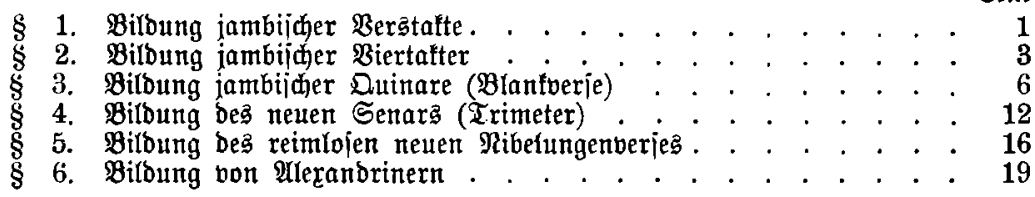

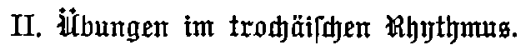

§ 7. Bilbung troduäifłer Berstafte . . . . . . . . . . . . . 20

$\S$ 8. Bilbung trođäifłer Biertafter . . . . . . . . . . . . . . . 21

§ 9. Bildung trođäifłer Suinare. . . . . . . . . . . . . . . 23

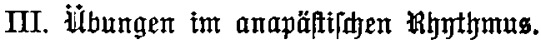

§ 10. Bildung anapäjtifđer $\mathfrak{B e r \xi t a f t e ~ . ~ . ~ . ~ . ~ . ~ . ~ . ~ . ~ . ~ . ~ . ~ . ~ . ~ . ~} 26$

$\$$ 11. Bilbung arapäftíĭer Biertafter. . . . . . . . . . . . . . 28

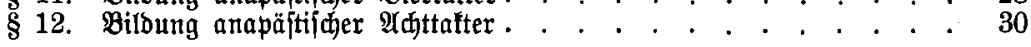

IV. İ̉bungen in beroilden bersmak.

§ 13. Bilbung von beutiden 9 Accentherametern . . . . . . . . . . 32

$\S$ 14. Bilbung von beutiden \$entametern ............ . . . 36

$\S$ 15. Berbindung bes Đerameters mit bem Bentameter . . . . . . 37

V. Übungen in gemi 「dten Rhynthmus.

§ 16. Bilbung logaöbijđjer (gemijđter) Berie . . . . . . . . . . 42 


\section{Bwriteg finuptfliid: : Keimver/f.}

1. Zilbungen in allitterierenden und affonierenden Derfen.

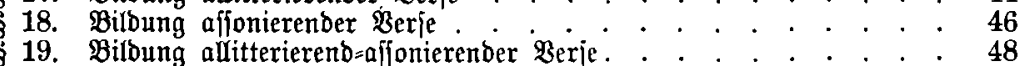

II. Übungen im łetm/udjen mud Reimbilden.

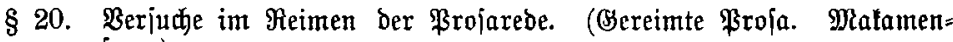
form) . . . . . . . . . . . . . . . . . 49

§ 21. Strengere Frorm Der Reime. (Borgejdriebene Reime. Bhajele) . 57

$\$ 22$. Bildung bon abwedjelno reimlojen und gereimten Berszzeilen. . . 62

23. Bildung von ununterbrodenen Reimberjen . . . . . . . . . 64

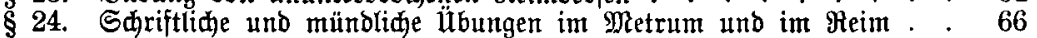

A. Mündlide umbilbung mittelhochbeutid)er (Sebichte . . . . 67

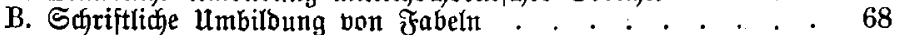

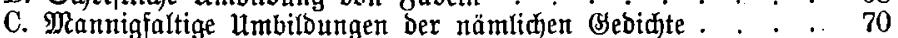

\section{Drittes fjauptftiidk: Strophenbildung.}

\$ 25. Einführung in bie Strophenbiloung . . . . . . . . . . . 72

\$26. I. Anjänge Der Strophentilbung und Entwifelung berjelben (\$hilo= fophie bes Strophenbaug).............. 73

II. Ränge ber ßerzzeilen und der Strophen: A. Beileriänge, B. Stro= phenlänge, C. Rormen für bie Beilen und Strophenlängen . . 74

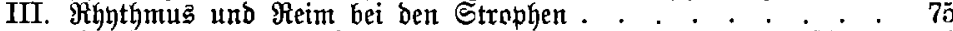

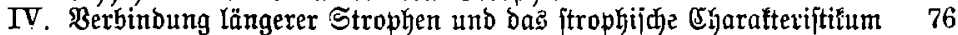

V. Einteilung dez Ssedidtiftoffes. . . . . . . . . . . . . . 77

\$27. Bildung jambijdjer Reintitrophen . . . . . . . . . . . . 78

$\$$ 28. Bilbung gereimter Ribelungentrophen (Rangzeilen) $\quad . \quad . \quad . \quad . \quad . \quad$. 82

$\S 29$. Bilduttg von Єtrophen aus gebroden gejđriebenen neuen Ribelungen= verjen . . . . . . . . . . . . . . . . . . . 80

\$ 30. Bilbung mittelhodjoutider Mibelungenitropher . . . . . . . 87

31. Sildung von গ̂lexandriner Ttrophen . . . . . . . . . . . . 89

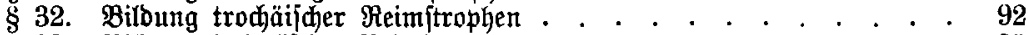

33. Bilbung baltylijaer Reimftrophen . . . . . . . . . . . . 95

34. Bildung trodjâil

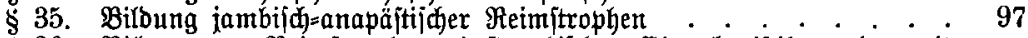

$\$ 36$. Bildung von Peimitrophen mit ftrophijaem Efarafterijtifum ober mit

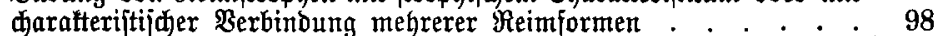

§ 37. Freie 21ccentverje zu freien Strophen vereint . . . . . . . . 101

\section{Điertes fanuptftiidk: Fremde moderne Strophen und Didftungg- formen. (\$iidlide formen.)}

§ 38. Bilbung bon Sonetten . . . . . . . . . . . . . . . . 104

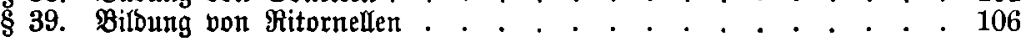




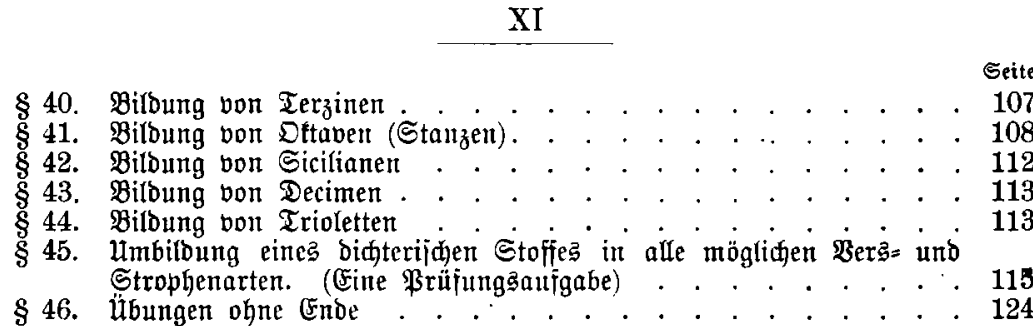

Eünftes fauptfitik: Antike Strophenformen.

\$ 47. Borbemerfungen und Stellungnalume . . . . . . . . . . . 125

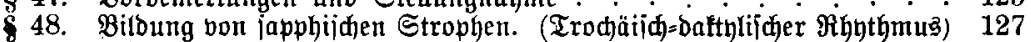

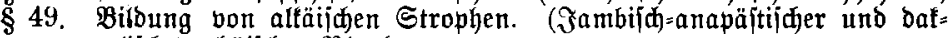

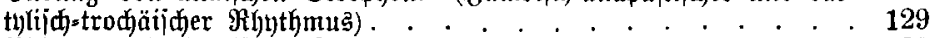

50. Bilbung a Bflepiadeijher Strophen . . . . . . . . . . . . 130

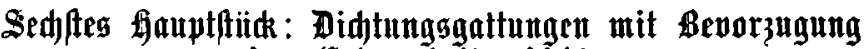 des Gelegenileritsgrdidits.}

\$51. Wie entfterht ein Hedidgt?. . . . . . . . . . . . . . . 133

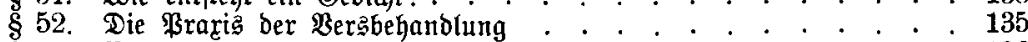

ร3. Borbemerfungen zu ben Bselegenheitżgediaten . . . . . . . . 136

I. Gedidjte aus Dem Bereidje der Didaktik.

§54. Bilbung bon Rätieln aller Formen . . . . . . . . . . 137

$\S 55$. Biĺbung von Epigrammen. (Stammbudjuers. Taufiprud). Trint= \{prud) . . . . . . . . . . . . . . . . . 141

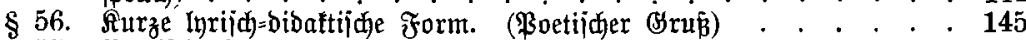

57. Poetijue Epiitel. (श्An einen $\left.\mathfrak{A}_{\mathfrak{r}} \mathrm{t}\right)$. . . . . . . 145

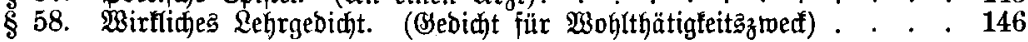

II. (5edidjte aus Dem Bereidje Der Mnrik.

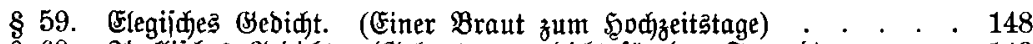

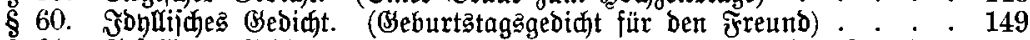

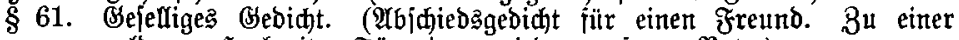
golbenen Đodfzeit. Für einen wiebergenejenen Bater) . . . . . 151

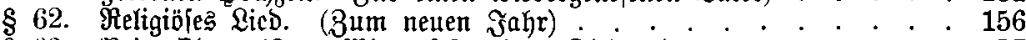

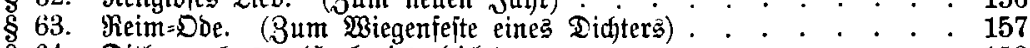

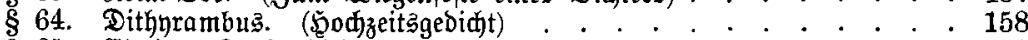

$\S$ 65. Elegie. (Troitgediut)

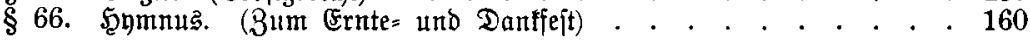

III. (Gedidjte aus Dem Bereidje deL OEpik.

§ 67. Poetijđe Erzählung. . . . . . . . . . . 161 


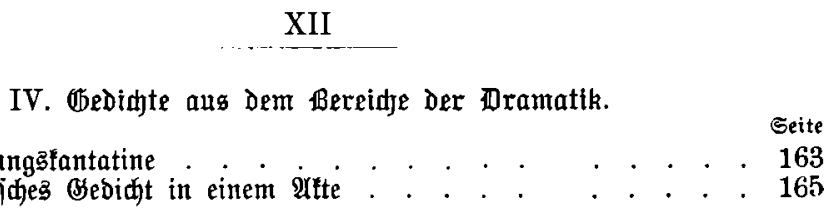

Sirbenteg fiauptftiidk: Đie prafis Der Đialektpoefir. (Winke, Gefidjtspunkte, fiandgriffe.)

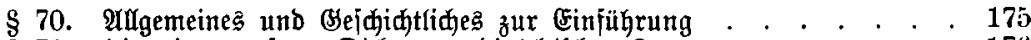

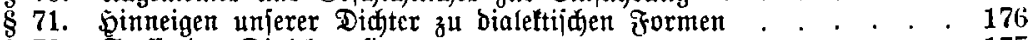

\$ 72. Stoffe ber Dialettpoefie . . . . . . . . . . . . . 177

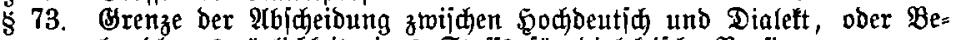

Ganblungs̄möglidfeit eines Stoffa für bialeftifđe Poefie. . . . . 178

\$ 74. Behandlung Der હtoffe. . . . . . . . . . . . . . 178

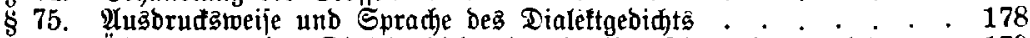

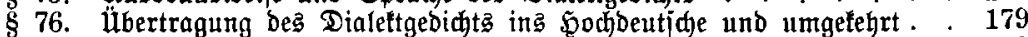

\$7. Anforberungen an ben Dialeftbichter . . . . . . . . . . . 183

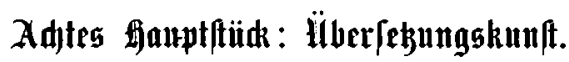

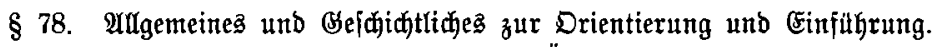

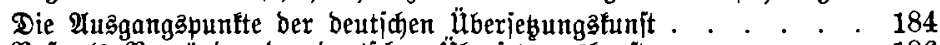

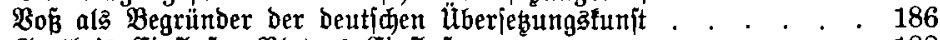

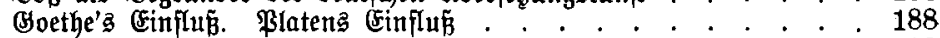

I. Griedijdye Didfter . . . . . . . . . . . . . . . . . . 188

a. Epif . . . . . . . . . . . . . 188

b. Eriedijde Lyrif . . . . . . . . . . . . . . . . 190

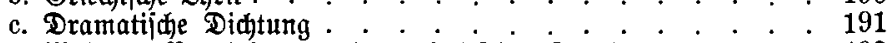

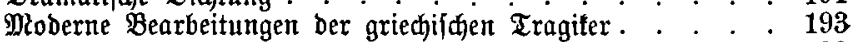

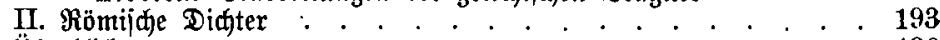

überblid

§ 79. Ânjorderungen unठ Brundiäke . . . . . . . . . . . . . 197

A. Anforberungen an bie überjebung. . . . . . . . . . . 198

B. Anforberungen alt ben überięer und Anleitung . . . 203

$\S 80$. Finblife in bie Beheimniffe ber überiekerpraris. (ந̧antogriffe, Methobe ber überjęerfeile $2 c$.) . . . . . . . . . 209

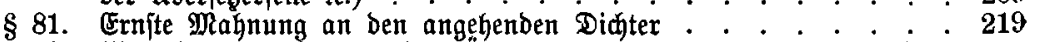

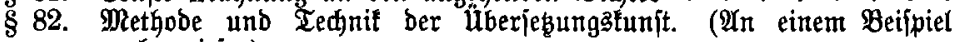
nadgewiejen) . . . . . . . . . . . . . . . . . . . 219

über[etrungsper[udje aus veridjiedenem Spraden:

\$ 83. Briedifłe Epradje. A. Überiegungen aus ber Epif. . . . . . . 229

B. " " " Qnrif . . . . 231

§ 84. Sateinifue Spradie. . . . . " " Tragöbie . . . 233

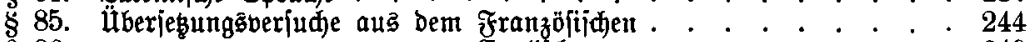

$\$ 86 . \quad " \quad "$ "Englijhen . . . . . . . . . . . . . 249

$\$ 87$. 


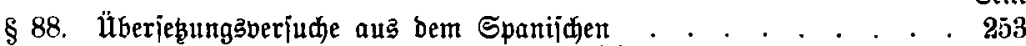

\$ 89.4 " " "

$\$ 90$. " " " "Shmebifaen . . . . . . . . . 260

\section{Heunteg fountftiidk: Selbftkritik und didterifate frile.}

8 91. Ungeborenes Bentie. Die Selbjtfritif Der nambafteften Didjter . . 264

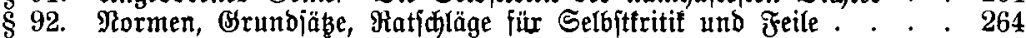

\$ 93. Fraftijhe Radmeiije Der Selbitfritil und ber bidterijahen Feile an guten Beijpiełen . . . . . . . . . . . . . . . . . 26ó

8 94. Žeile einzelter Berje und Strophen . . . . . . . . . . . 266

a. Shifler. . . . . . . . . . . . . . . . . . . 266

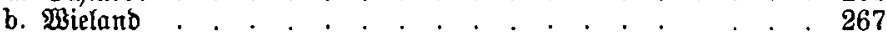

c. Seifing . . . . . . . . . . . . . . . . . 268

d. Slopitod . . . . . . . . . . . . . . . . . . 269

e. Яörner . . . . . . . . . . . . . . . 270

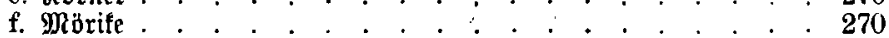

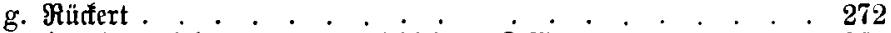

\$ 95. Feile ober umarbeitung ganzer Bsebidte. ¿ejing : . . . . 273

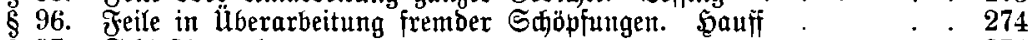

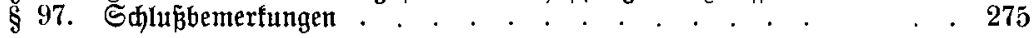



田i

Cedhutik Dor Midjtkutuft. 
Im Fleif tann bid bie Biene meiltern,

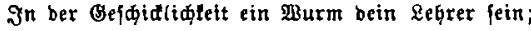

Dein $\mathfrak{B}$ iffen tcileft bu mit vorgezognen Beiftern:

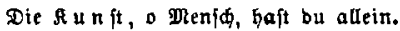

Sdiller.

Die Sunjt bleibt Runjt! Mer fie nibt burфgebađit,

Der tann ji teinen Rünftler nennen.

Boetfe.

Der ift ber Meifter, welder leidit volforadt Gat,

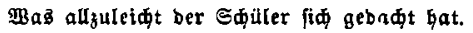

(Hisbert Frhr. v. Binde. 